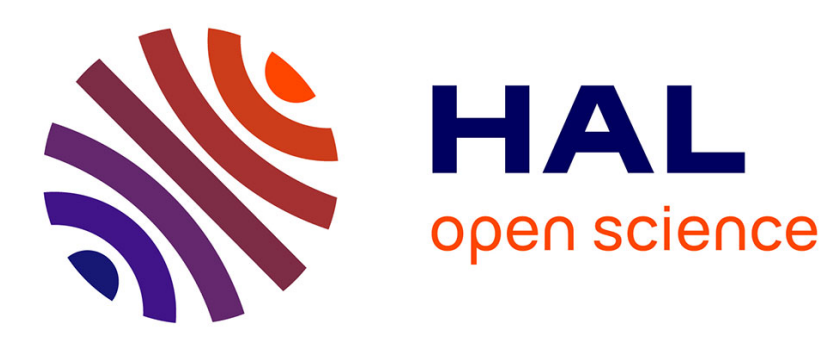

\title{
Semi-Conducteurs III-V et Microélectronique
}

Robert Adde, Jean-Claude Charpentier

\section{To cite this version:}

Robert Adde, Jean-Claude Charpentier. Semi-Conducteurs III-V et Microélectronique. Revue de Physique Appliquée, 1987, 22 (8), pp.785-785. 10.1051/rphysap:01987002208078500 . jpa-00245610

\section{HAL Id: jpa-00245610 https://hal.science/jpa-00245610}

Submitted on 1 Jan 1987

HAL is a multi-disciplinary open access archive for the deposit and dissemination of scientific research documents, whether they are published or not. The documents may come from teaching and research institutions in France or abroad, or from public or private research centers.
L'archive ouverte pluridisciplinaire HAL, est destinée au dépôt et à la diffusion de documents scientifiques de niveau recherche, publiés ou non, émanant des établissements d'enseignement et de recherche français ou étrangers, des laboratoires publics ou privés. 


\section{Semi-Conducteurs III-V et Microélectronique}

\section{Préface}

Les premières Journées Nationales Semi-Conducteurs III-V se sont tenues du 7 au 9 janvier 1987 à Aussois. Elles ont réuni 180 participants des équipes C.N.R.S.-Universités, des laboratoires publics (C.N.E.T.) et industriels. A cette occasion, les actions menées et les résultats obtenus sur les thèmes principaux de ce domaine très pluridisciplinaire ont été confrontés et discutés : élaboration des matériaux, mécanismes physiques, conception et technologie de composants et circuits. Il est clairement apparu que la rencontre de spécialistes venant d'horizons fondamentaux et appliqués est fructueuse et doit être amplifiée, notamment pour exploiter toutes les potentialités des nouvelles microstructures et des technologies les plus avancées de la microélectronique.

Ce numéro spécial rassemble un certain nombre d'articles soumis à la Revue de Physique Appliquée à l'occasion de cette manifestation. Cette initiative a été prise à la fin de 1986, ce qui explique que certaines équipes n'y participent pas, leurs résultats les plus récents étant déjà en cours de publication ou devant paraître dans le cadre des Journées Nationales Microondes 1987. La quarantaine d'articles retenus couvre un champ très large et témoigne du dynamisme de la recherche dans le domaine de la Microélectronique des Semi-Conducteurs III-V au sens le plus large du terme. Cette publication spéciale apparaît répartie sur deux numéros de la Revue, afin d'assurer une édition rapide.

Robert Adde, Jean-Claude Charpentier 